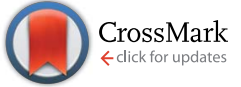

Cite this: RSC Adv., 2017, 7, 77

Received 5th October 2016 Accepted 18th November 2016

DOI: 10.1039/c6ra24777f

www.rsc.org/advances

\title{
The effect of the nature of organic acids and the hydrodynamic conditions on the dissolution of $\mathrm{Pb}$ particles
}

\begin{abstract}
S. Bendebane, L. Tifouti and S. Djerad*
A series of experiments were conducted to examine the effects of three organic acids (propionic, malic and citric acids) on the rate of $\mathrm{Pb}$ dissolution in order to evaluate its potential environmental pollution risk. The effects of acid concentration, agitation device, temperature and hydrodynamic conditions were investigated. The results show that propionic acid which contained the lowest number of functional groups had the greatest effect on $\mathrm{Pb}$ dissolution. In fact, it dissolved 100\% of Pb particles after $35 \mathrm{~min}$ at the concentration of $5 \mathrm{mM}$ at $25{ }^{\circ} \mathrm{C}$ while 92.1 and $47.6 \%$ were dissolved by malic and citric acid, respectively, under the same conditions. It was also found that the effect of the nature of the acid interfered with that of particle size and the hydrodynamic conditions making the system complicated to interpret totally.
\end{abstract}

\section{Introduction}

Management of solid waste is one of the major challenges worldwide. Inadequate collection, recycling or treatment and uncontrolled disposal of waste in dumps lead to severe hazards. This situation is especially serious in developing countries where the use of appropriate treatment and disposal technologies is rare and the lack of suitable treatment is responsible for unsatisfactory solid waste management. ${ }^{1}$ In North Africa, the population has a Mediterranean diet and consumes a lot of fruit and vegetables whose wastes are found later dumped in landfills co-disposed with metals. ${ }^{2}$ They undergo anaerobic fermentation which results in the emission of greenhouse gases, like methane, and acid leachates that may accelerate the transport of potentially toxic metals to both surface and groundwater.

Lead $(\mathrm{Pb})$ is a metal that occurs naturally in the earth's crust, but human activity such as mining and burning fossil fuels has caused it to become more widespread. It contaminates soil through vehicle exhausts, sewage-sludge biosolids and mining. ${ }^{3}$ Lead particles that settle on the soil can last for years. Its presence is considered to be a risk to human health when soil concentrations exceed 400-500 $\mathrm{mg} \mathrm{Pb} \mathrm{kg}^{-1}$ soil $^{4}$ (EPA, 2001) and highly contaminated soils may have $\mathrm{Pb}$ concentrations $>10000 \mathrm{mg} \mathrm{kg}{ }^{-1}$. Toxicity from Pb-contaminated soils primarily occurs from direct ingestion. Symptoms of lead poisoning in adults include high blood pressure, muscle pain, declines in mental functioning, memory loss and other.

Laboratory of Environmental Engineering, Department of Chemical Engineering, University of Annaba, P. O. Box 12, Annaba 23000, Algeria. E-mail: s_djerad@ hotmail.com
Low-molecular-weight organic acids are common products in soils, they are released as exudates by plant roots in the rhizosphere and, through chelating reactions, promote the dissolution of minerals and facilitate the uptake of dissolved elements into plants. ${ }^{6,7}$ They have also the faculty to increase the mobility of metallic contaminants in soils polluted by mineral wastes. Their concentration is generally in the range of $10^{-3}$ to $10^{-5} \mathrm{M},{ }^{8,9}$ but can be higher than millimolar under litter ${ }^{10}$ and during the anaerobic fermentation of organic wastes. The most commonly reported organic acids are citric, formic, propionic, acetic, oxalic, malic, and succinic. ${ }^{11}$ In the literature, lead degradation has been studied with organic acids such as formic and acetic acids in gaseous form formed as by-products of wood degradation. ${ }^{\mathbf{1 2 - 1 5}}$ The role of volatile organic products on metal degradation is recognized ${ }^{\mathbf{1 6}}$ but their effect on aqueous phase was not extensively studied. Some papers were found dealing with $\mathrm{Pb}$ leaching in framework of metal recovery from acid battery using inorganic acids as leaching reagent ${ }^{17,18}$ while other used organic acids as green process. ${ }^{19-21}$ Often, the studies dealing with metal degradation are conducted in static media and those dealing with the recovery of metals are conducted under one type of stirring device. Changing stirring device may change the hydrodynamic conditions and affect the progress of the dissolution reactions. There is a lack in literature about this parameter. On the other hand, it is known that the solubility of most heavy metals is significantly enhanced by decreasing $\mathrm{pH}$ values or by adding chelating agents that bond with the metal to form stable, ring-like coordination complexes called chelates. ${ }^{22}$ In this study we have checked this assumption by testing three organic acids (propionic, malic and citric acids) in the dissolution of lead particles. 
Table 1 Composition of $\mathrm{Pb}$ used in this study

\begin{tabular}{lllllllll}
\hline Element & $\mathrm{Ag}$ & $\mathrm{Fe}$ & $\mathrm{Bi}$ & $\mathrm{Cd}$ & $\mathrm{Cu}$ & $\mathrm{Ni}$ & $\mathrm{Sn}$ & $\mathrm{Pb}$ \\
$\%$ & 0.2 & 0.09 & 0.3 & 0.03 & 0.3 & 0.07 & 0.01 & 99
\end{tabular}

\section{Experimental}

Lead powder (Sigma Aldrich, $\geq 99 \%$ ) with dimension of 325 mesh was used without pretreatment. The composition of $\mathrm{Pb}$ is given in Table 1. Propionic acid $\mathrm{C}_{3} \mathrm{H}_{6} \mathrm{O}_{2}(99 \%$, Sigma Aldrich), malic acid $\mathrm{C}_{4} \mathrm{H}_{6} \mathrm{O}_{5}(\geq 98 \%$, Sigma Aldrich) and citric acid $\mathrm{C}_{6} \mathrm{H}_{8} \mathrm{O}_{7}$ (99\%, Sigma Aldrich) were used as received. Deionized water was used to prepare all aqueous solutions. Tests of lead dissolution were performed in a Pyrex glass reactor in which a mass of $\mathrm{Pb}$ was contacted with a volume of acid solution under mechanical agitation. The dissolution rate was followed by the release of $\mathrm{Pb} . \mathrm{Pb}^{2+}$ present in aqueous solution was determined by volumetric method using NET as indicator. The data presented are an average of three test replicates with an error of $5 \%$. SEM analyses were performed by using a mini SEM (Phenom Pure, The Netherlands).

\section{Results and discussion}

\section{Effect of variables on dissolution}

$0.1 \mathrm{~g}$ of lead powder was contacted with $250 \mathrm{~mL}$ of each acid solution at $25{ }^{\circ} \mathrm{C}$ and $350 \mathrm{rpm}$. Different acid concentrations were tested: $5-10-20 \mathrm{mM}$ and $50 \mathrm{mM}$ corresponding to $n_{\text {acid }} / n_{\mathrm{Pb}}$ $=2.6-5.2-10.4$ and 26 respectively. The results (Fig. 1a-d) show that dissolved $\mathrm{Pb}$ increased with increasing the concentration of the organic acids. $\mathrm{Pb}$ release was dependent on the nature of the reagent since propionic acid enhanced the dissolution to the greater extent while citric acid was the weaker reagent regardless of the conditions used.

Plots of $\mathrm{Pb}$ dissolution versus time showed different distinct regimes in the dissolution process; at $1 \mathrm{~min}$ the dissolution attained $78.3,70.9$ and $29.5 \%$ with propionic, malic and citric acids respectively. This first period was followed by a second one [1-5 min] in which the slopes of lines decreased indicating a diminution in the dissolution rate. At $t>5 \mathrm{~min}$ the slopes of lines decreased again and the reaction progressed until reaching $100 \%$ with propionic and malic acids and stopped with citric acid after a certain time depending on its concentration.

Plots of $\mathrm{pH}$ obtained with the three acids during $\mathrm{Pb}$ dissolution show different behaviors. In fact a rapid increase in $\mathrm{pH}$ values was clearly observed in the first few minutes with propionic acid (Fig. 2a) followed to a lesser extent by malic acid (Fig. 2b) indicating a clear involvement of protons in the dissolution reaction in both cases while a very slight increase in pH was observed with citric acid (Fig. 2c). After that $\mathrm{pH}$ values registered a plateau with the three acids while the dissolution was still in progress as shown in Fig. 1a-d. $\mathrm{pH}$ values remained in acidic range $(\mathrm{pH}<5)$. This may indicate that protons were present in the solution but they could not react with the solid surface.

The effect of temperature was studied in range $25-50{ }^{\circ} \mathrm{C}$ at $350 \mathrm{rpm}$ with $5 \mathrm{mM}$ as acid concentration (Fig. 3). The results plotted at $20 \mathrm{~min}$ of reaction show that $\mathrm{Pb}$ dissolution registered 44,85 and $94.8 \%$ at $25{ }^{\circ} \mathrm{C}$ with citric, malic and propionic acids respectively and increased to $55.3,91$ and $100 \%$ at $35{ }^{\circ} \mathrm{C}$ with the same acids. The effect of temperature on the dissolution rate was slight in the three cases.

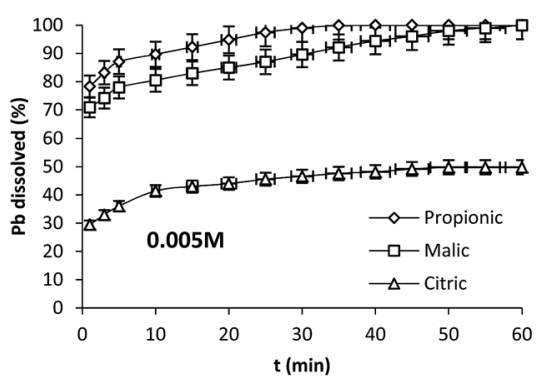

(a)

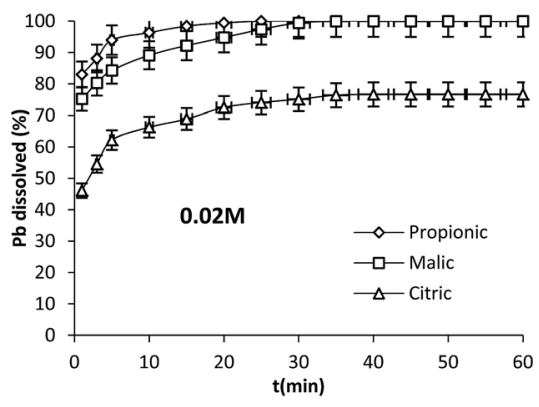

(c)

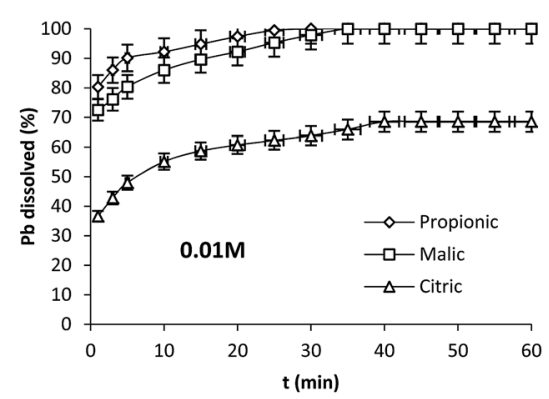

(b)

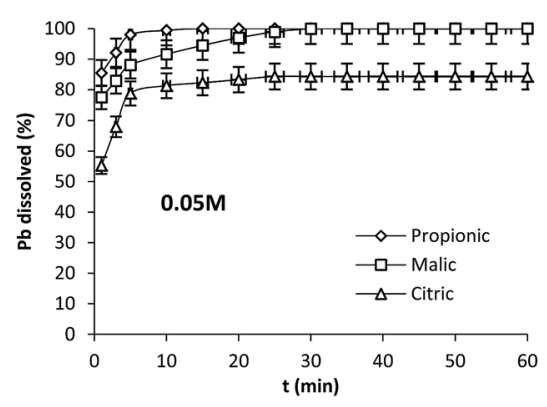

(d)

Fig. 1 Effect of acid concentration on Pb dissolution. Operation conditions: $0.1 \mathrm{~g} \mathrm{~Pb}, 25^{\circ} \mathrm{C}, 350 \mathrm{rpm}, \mathrm{V}=250 \mathrm{~mL}$. 


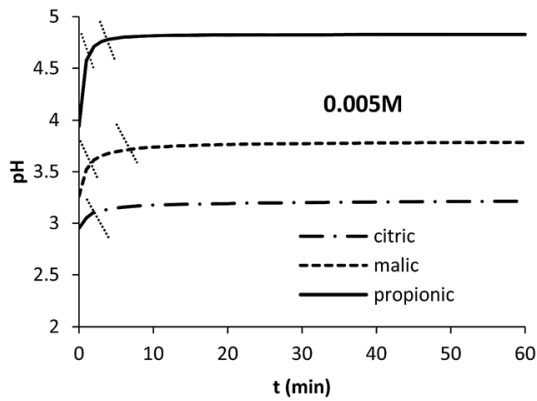

(a)

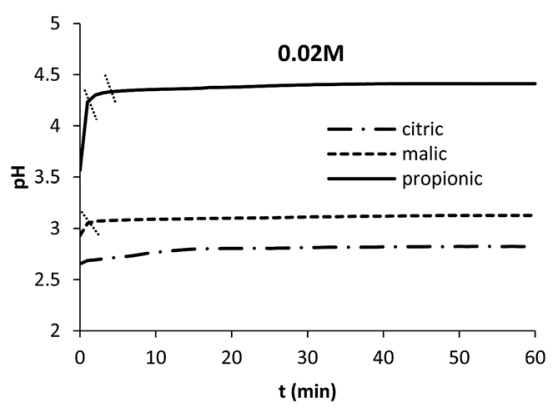

(c)

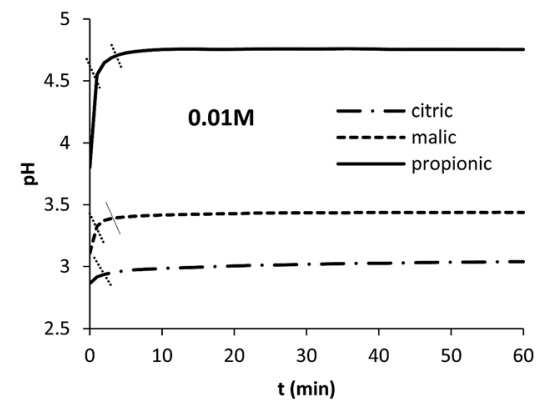

(b)

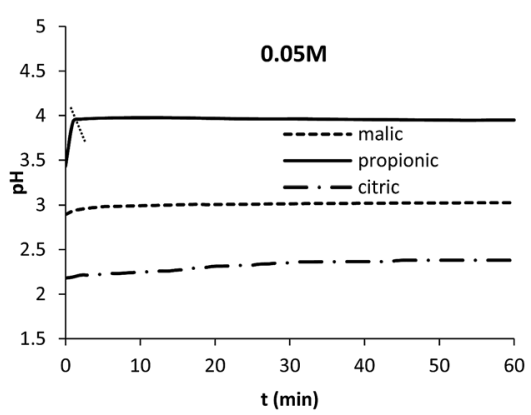

(d)

Fig. 2 Evolution of $\mathrm{pH}$ during $\mathrm{Pb}$ dissolution with the organic acids at different concentrations. Operation conditions: $0.1 \mathrm{~g} \mathrm{~Pb}, 25^{\circ} \mathrm{C}, 350 \mathrm{rpm}, \mathrm{V}$ $=250 \mathrm{~mL}$.

$\mathrm{Pb}$ seems to be effectively dissolved in weak acids. In fact comparing $\mathrm{p} K_{\mathrm{a}}$ values of the three organics acids and their efficiency in $\mathrm{Pb}$ dissolution shows that they follow the same order: propionic $\left(\mathrm{p} K_{\mathrm{a}}=4.87\right)>$ malic $\left(\mathrm{p} K_{\mathrm{a} 1}=3.46\right)>\operatorname{citric}\left(\mathrm{p} K_{\mathrm{a} 1}\right.$ $=3.13$ ).

To assess the importance of $\mathrm{pH}$ on lead dissolution other experiments were carried out with sodium citrate $\mathrm{C}_{6} \mathrm{H}_{6} \mathrm{Na}_{2} \mathrm{O}_{7^{-}}$ $\cdot 1.5 \mathrm{H}_{2} \mathrm{O}$ (Sigma Aldrich, $\geq 99 \%$ ). In the first experiment $250 \mathrm{~mL}$ of sodium citrate at the concentration of $5 \mathrm{mM}$ was contacted with $0.1 \mathrm{~g}$ of lead powder at $25{ }^{\circ} \mathrm{C}$ and $350 \mathrm{rpm}$. In the second one the same amount of sodium citrate was added in solid form to citric acid at $5 \mathrm{mM}$ after $20 \mathrm{~min}$ of reaction with $\mathrm{Pb}$.

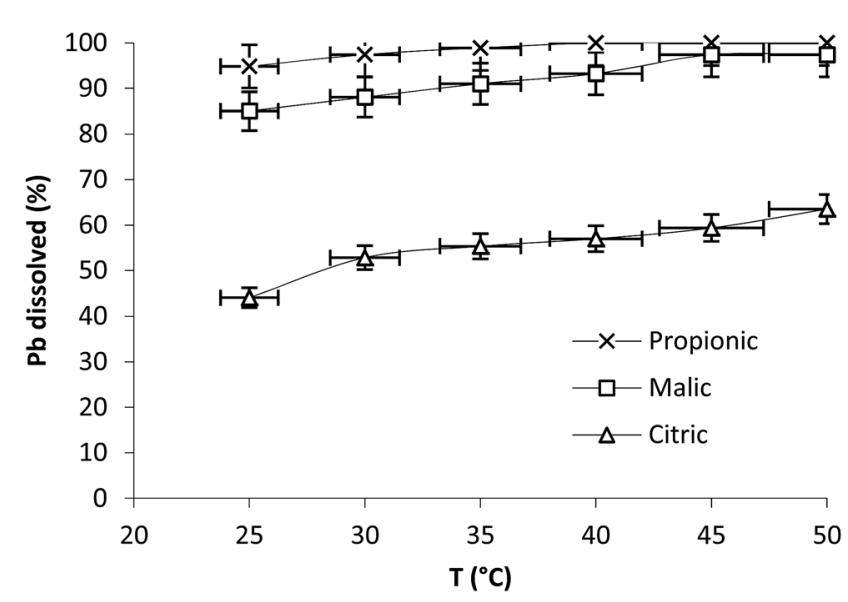

Fig. 3 Effect of temperature on $\mathrm{Pb}$ dissolution with the three organic acids after $20 \mathrm{~min}$. Operation conditions: $0.1 \mathrm{~g} \mathrm{~Pb}, t=20 \mathrm{~min}, 350 \mathrm{rpm}$, $V=250 \mathrm{~mL}, C_{\text {acid }}=5 \mathrm{mM}$.
The results show that the dissolution of $\mathrm{Pb}$ with citric acid alone reached $49 \%$ after $60 \mathrm{~min}$. The addition of sodium citrate after 20 min of reaction between citric acid and $\mathrm{Pb}$ enhanced the dissolution to $62 \%$ while sodium citrate alone dissolved $75 \%$ of $\mathrm{Pb}$ after the same period of time (Fig. $4 \mathrm{a}$ ). Sodium citrate was better in $\mathrm{Pb}$ dissolution than citric acid.

The $\mathrm{pH}_{0}$ of sodium citrate solution at $5 \mathrm{mM}$ was 5.5 it increased up to 6.2 after 60 min of reaction with $\mathrm{Pb}$ while $\mathrm{pH}$ of citric acid at $5 \mathrm{mM}$ increased from 3 (at $t=0 \mathrm{~min}$ ) to 3.2 after the same period of time (Fig. 4b). The solution of citric acid was more acid than that of sodium citrate while sodium citrate was more effective in lead dissolution. These results confirmed those obtained with the three acids which showed that lead dissolution is favored by mild acidity under the conditions used in this study. This behavior differs from that of many other minerals that were found to be effectively dissolved under strong acidic conditions. ${ }^{23,24}$

The main objective of this study was to investigate $\mathrm{Pb}$ dissolution in organic acids. However, it can be of interest to study its behavior in mineral acid such as $\mathrm{HNO}_{3}$. For this task the same operation conditions $\left(0.1 \mathrm{~g}, 25^{\circ} \mathrm{C}, 5 \mathrm{mM}\right)$ were used to investigate $\mathrm{Pb}$ dissolution in $\mathrm{HNO}_{3}$ (Fig. 5a). Three distinct regions in which the dissolution was marked by the variation in slopes were observed. $\mathrm{pH}$ values increased until stabilization at around $30 \mathrm{~min}$ indicating that the involvement of protons in this case was more important than with the organic acids (Fig. 5b).

In the literature the main studies devoted to lead corrosion were carried out under static conditions because they are considered to be more closely representative of natural 


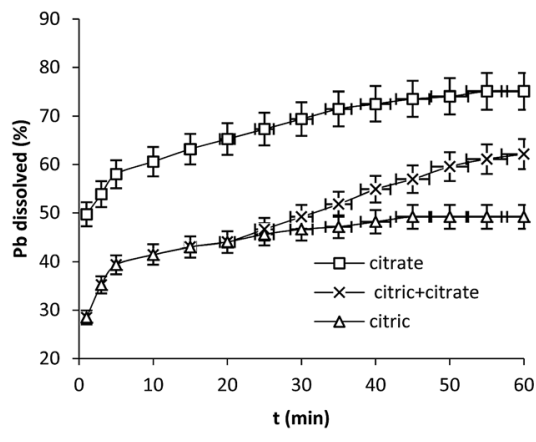

(a)

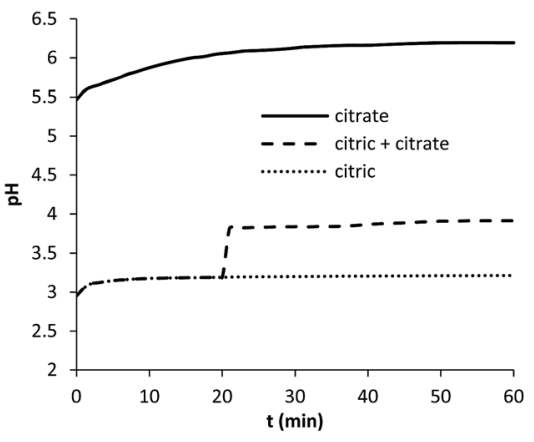

(b)

Fig. 4 Effect of the addition of citrate ligand on $\mathrm{Pb}$ dissolution (a) and on the evolution of $\mathrm{pH}(\mathrm{b})$ during $\mathrm{Pb}$ dissolution. Operation conditions: $0.1 \mathrm{~g} \mathrm{~Pb}, 25^{\circ} \mathrm{C}, 350 \mathrm{rpm}, V=250 \mathrm{~mL}, \mathrm{C}_{\text {acid }}=5 \mathrm{mM}, \mathrm{C}_{\text {citrate }}=5 \mathrm{mM}$.

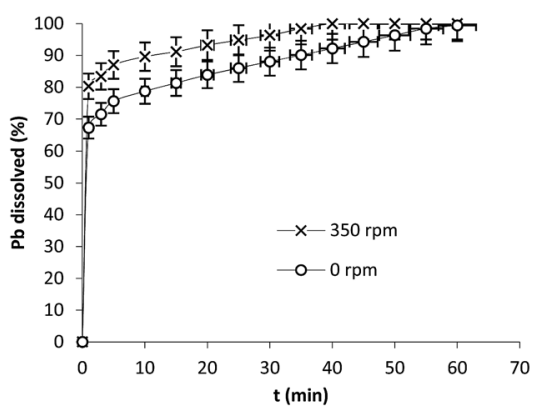

(a)

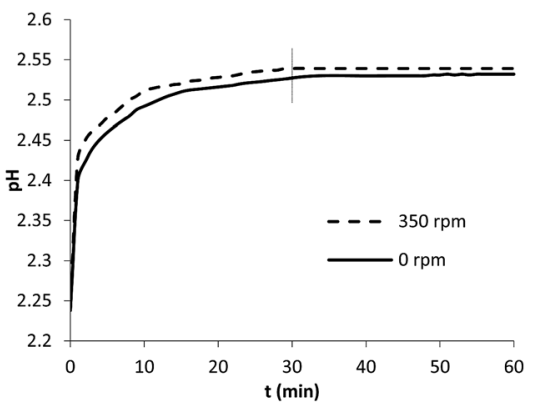

(b)

Fig. 5 Dissolution of $\mathrm{Pb}$ in $\mathrm{HNO}_{3}(\mathrm{a})$ and the evolution of $\mathrm{pH}(\mathrm{b})$ in the presence and absence of stirring. Operation conditions: $0.1 \mathrm{~g} \mathrm{~Pb}, 25^{\circ} \mathrm{C}, \mathrm{V}=$ $250 \mathrm{~mL}, \mathrm{HNO}_{3}$ at $5 \mathrm{mM}$.

corrosion conditions. However, investigating the dissolution of metals under dynamic conditions may be of interest to better understand the effect of flowing conditions.

\section{Effect of hydrodynamic conditions}

Transport processes existing in the environment are the consequence of diffusion or convection of chemical species. It is known that the dissolution rate of a solid in an aqueous environment depends upon the frequency of collisions occurring between fluid molecules and the solid. It is also known that under the same stirring speed, the frequency of collision inside a liquid system increases with decreasing the volume of solution.

In an attempt to evaluate the effect of the hydrodynamic conditions, other experiments were carried out with propionic and citric acids in which $75 \mathrm{~mL}$ at $16.7 \mathrm{mM}, 100 \mathrm{~mL}$ at $12.5 \mathrm{mM}$, $150 \mathrm{~mL}$ at $8.3 \mathrm{mM}$ and $250 \mathrm{~mL}$ at $5 \mathrm{mM}$ were contacted with the same amount of $\mathrm{Pb}(0.1 \mathrm{~g})$ at $25{ }^{\circ} \mathrm{C}$ in the presence $(350 \mathrm{rpm})$ and absence $(0 \mathrm{rpm})$ of stirring (Fig. $6 \mathrm{a}-\mathrm{d})$. In both cases the same mole number of acids was in contract with the same amount of lead. More or less molecules of water were present to increase or decrease the total volume of the solution.

The results show two different behaviors; in the presence of agitation the dissolution of $\mathrm{Pb}$ in the presence of propionic acid was enhanced by increasing the volume of the solution while it decreased under the same conditions with citric acid (Fig. 6ab). In the absence of agitation the dissolution of $\mathrm{Pb}$ decreased with increasing the volume of propionic acid on the contrary of citric acid (Fig. 6c-d).

Our results have shown that the progress of the reaction differs strongly whether the dissolution occurred in static or in dynamic conditions. To get deeper knowledge on the behavior of $\mathrm{Pb}$ during dissolution under stirring, we have extended our experiments to the effect of two types of stirring (mechanical and magnetic) under the same conditions: $100 \mathrm{rpm}$ and $25{ }^{\circ} \mathrm{C}$ by using $250 \mathrm{~mL}$ of propionic and citric acids at $5 \mathrm{mM}$. The mechanical stirrer was fitted with 4 inclined paddles $\left(45^{\circ}\right.$ and $2 \mathrm{~cm}$ length each) while magnetic stirring was carried out with a magnetic bar with $2.5 \mathrm{~cm}$ length. The results shown in Fig. 7a and $b$ indicate that in the case of citric acid the dissolution attained $100 \%$ after 55 min with magnetic stirring and stabilized at $72 \%$ with mechanical one. With propionic acid it attained $100 \%$ after $7 \mathrm{~min}$ and $90 \%$ after $60 \mathrm{~min}$ with magnetic and mechanical stirring respectively. With both acids a clear improvement in the dissolution was observed with magnetic stirring. The highest dissolution efficiency obtained with citric acid mechanically stirred was $84 \%$ obtained after 60 min of reaction using the concentration of $50 \mathrm{mM}$ under $350 \mathrm{rpm}$ (Fig. 1d) while total dissolution was observed with magnetic stirring at lower agitation speed $(100 \mathrm{rpm})$ and only $5 \mathrm{mM}$. 


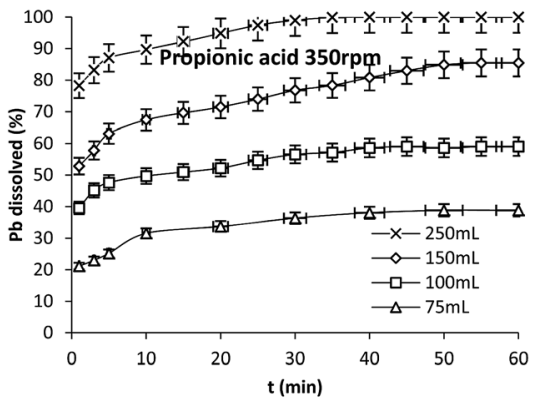

(a)

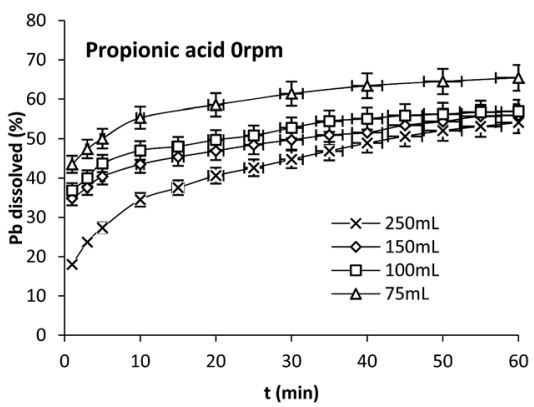

(c)

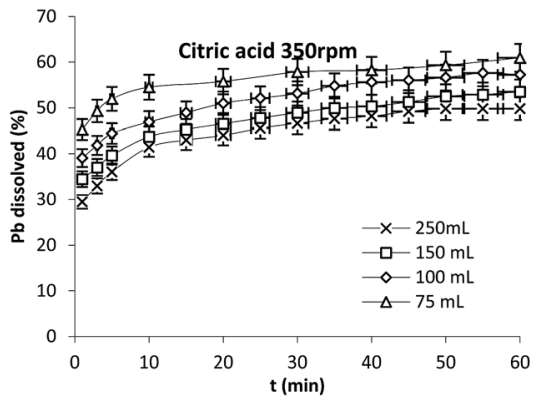

(b)

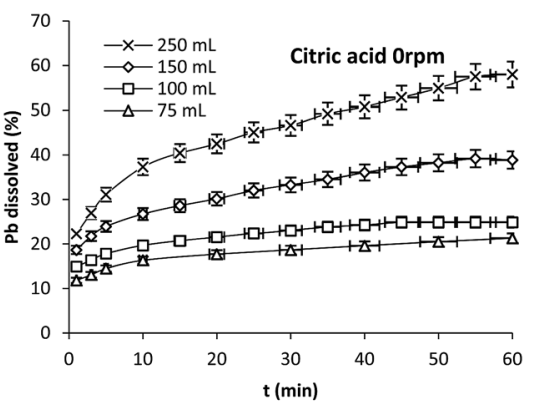

(d)

Fig. 6 Effect of the hydrodynamic conditions on Pb dissolution with propionic and citric acids. (a and b) $350 \mathrm{rpm}$, (c and d) $0 \mathrm{rpm}$. Operation conditions: $0.1 \mathrm{~g} \mathrm{~Pb}, 25^{\circ} \mathrm{C}, n_{\text {acid }}=1.25 \times 10^{-3} \mathrm{~mol}$.

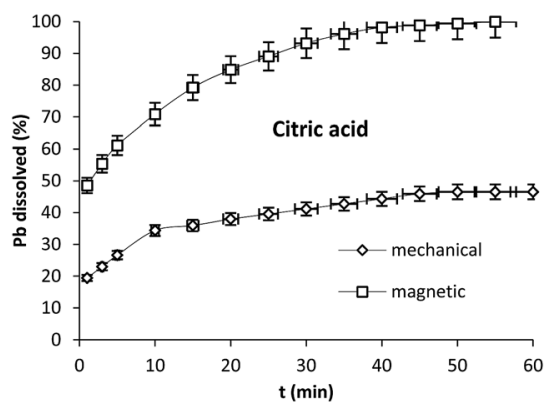

(a)

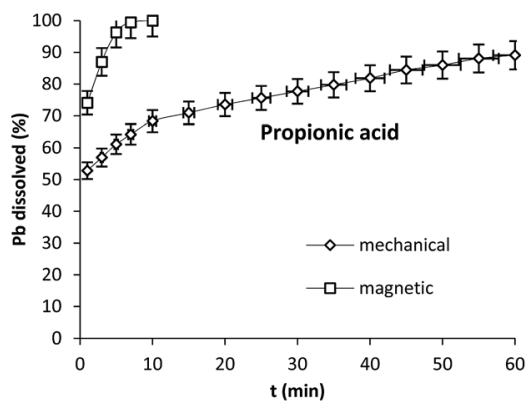

(b)

Fig. 7 Effect of mechanical and magnetic stirring on $\mathrm{Pb}$ dissolution with citric (a) and propionic acid (b) operation conditions: $0.1 \mathrm{~g} \mathrm{~Pb}, 25^{\circ} \mathrm{C}$, $100 \mathrm{rpm}, V=250 \mathrm{~mL}, C_{\text {acid }}=5 \mathrm{mM}$.

It is worth nothing that with mechanical stirring, the plots obtained were straight lines with slopes varying after each period of time while with magnetic one the plots were curved.

\section{SEM analysis}

Generally a powder of any material can be formed by particles with different sizes. Visual observation of the behavior of $\mathrm{Pb}$ particles during dissolution has shown that as the reaction begins the solution became trouble indicating the dispersion of fine particles of $\mathrm{Pb}$ into the solution. At the same time the rest of the powder accumulated rapidly under the paddle forming agglomerate in the central position of the reactor. After about $1 \mathrm{~min}$ the solution became transparent and remained so up to the end of the experiment. The volume of the agglomerate located in the centre decreased with time until it disappeared (with propionic and malic acids). These observations indicate that the smallest particles tend to float within the solution until their total dissolution and the particles with greater size (dense particles) tend to stay in the bottom of the reactor.

Fig. 8a shows an overview of $\mathrm{Pb}$ powder which is composed mainly by fines particles and three range of size can be observed in Fig. 8 b; small particles in the range $1-2 \mu \mathrm{m}$ which constitutes the main part of the powder, a second part of particles with size in range $10-20 \mu \mathrm{m}$ and a third and lower part of greater particles of about $40-50 \mu \mathrm{m}$. It is evident from both images that the fine particles are those floating into the mainstream and consequently the first to be dissolved by the organic acids. 


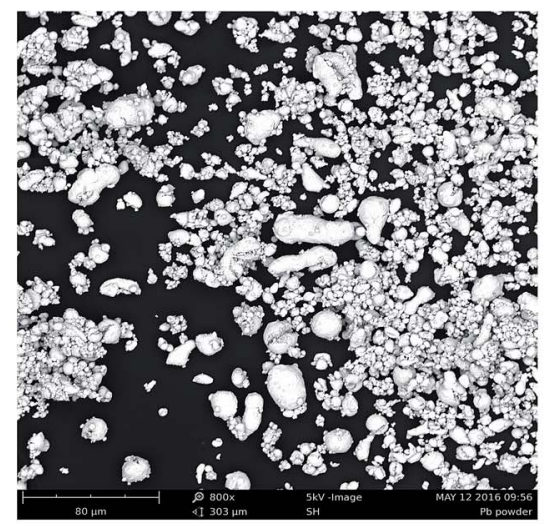

(a)

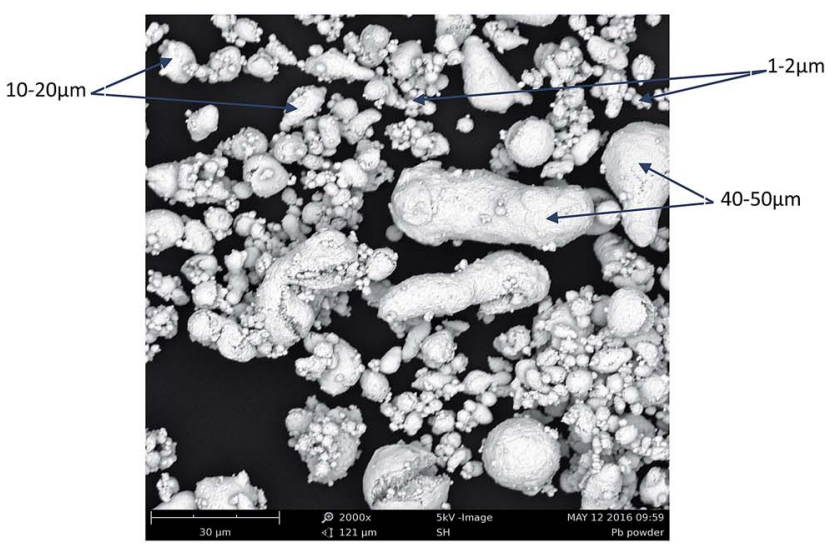

(b)

Fig. 8 SEM images of $\mathrm{Pb}$ powder.

\section{Discussion}

$\mathrm{Pb}$ dissolution was dependent on the acidity of the solutions, ligands structure, the functional groups they contain, the surface complexes they form and the size of the particles.

The structure of metal-ligand complexes is important because it orients towards a promoting or inhibiting dissolution process. In the literature, it was reported that the efficient ligands are those whose functional groups contain two or more oxygen donors and which can form bi- or multidentate mononuclear surface chelates. ${ }^{25}$ The faster dissolution of metals by such compounds is assumed to be due to the interaction of functional groups with metals that results in the formation of stable 5- or 6-membered ring structures. ${ }^{26}$ Pohlman and Coll ${ }^{27}$ have shown that di- and tri-carboxylic acids containing hydroxyl functional groups dissolve metal such as $\mathrm{Al}, \mathrm{Mn}$, and Fe from soils faster than similar organic compounds with other functional group combinations. Furrer and Stumm ${ }^{28}$ and Stumm ${ }^{29}$ proposed a mechanism of metal dissolution as follows: strong interaction between the ligand and a superficial metal atom transfers considerable electron density into the coordination sphere of the metal cation. This polarization weakens the bond leaving the complexed metal cation more susceptible to release from the surface.
However, our results show strictly the contrary of the assumption given above since the dissolution rate increased with the acid which contains less functional groups. In fact, propionic, malic and citric acids contain respectively one $\left(\mathrm{CH}_{3} \mathrm{CH}_{2} \mathrm{COOH}\right)$, two (HOOC- $\left.\mathrm{CH}_{2}-\mathrm{CHOH}-\mathrm{COOH}\right)$ and three $\left(\mathrm{HOOCCH}_{2}\right)_{2} \mathrm{C}(\mathrm{OH}) \mathrm{COOH}$ carboxylic groups. It is propionic acid which contains the lower number of functional group that was the most effective in $\mathrm{Pb}$ dissolution while citric acid which is known as strong dissolving agent was found to be a weak reagent. Ligand adsorbing on the surface can potentially have dual effects on the process of breaking metal-oxygen bonds. ${ }^{30}$ The weak dissolution rate observed with citric acid is interesting because it highlights the importance of adsorption in the dissolution process. The adsorption of species is related to the nature of electrostatic interactions. The measurement of PZC of $\mathrm{Pb}$ was realized with the same method reported elsewhere ${ }^{24}$ and the value was found to be 9.98. In this case the adsorption is favored by decreasing $\mathrm{pH}$ value. Thus, it is likely that citric acid which showed the highest acidity interacts strongly with $\mathrm{Pb}(\mathrm{a}$ basic metal) surface than propionic and malic acids and the release of $\mathrm{Pb}$ was consequently hindered. The importance of $\mathrm{pH}$ of the medium during dissolution was observed when citric acid and sodium citrate were tested under the same conditions. In fact, when the same molecule is used at $\mathrm{pH}_{0}=3$ (citric acid) and 5.5 (sodium citrate), it dissolved differently $\mathrm{Pb}$. Decreasing the strength of attraction between the solid surface and the fluid molecules by increasing the $\mathrm{pH}$ of the solution has probably improved the progress of the dissolution.

The values of equilibrium constant of $\mathrm{Pb}$ with organic acids were reported at $25^{\circ} \mathrm{C} .{ }^{31}$ The values of ML/M.L are as follows: $10^{-2.08}, 10^{-2.45}$ and $10^{-4.08}$ for propionic, malic and citric acids respectively. The values show that the reaction of lead with citric acid tends to form less products than with propionic and malic acids which corroborates our results. However, this is in contradiction with the assumption given by Furrer and Stumm. We believe that this is due to the differences in the conditions used that may radically change the results obtained. This was observed in this study. In fact, citric acid exhibited higher dissolution rate than propionic acid under the condition $(75 \mathrm{~mL}$ to $350 \mathrm{rpm}$ ) where it registered $52 \%$ against $25 \%$ with propionic acid after $5 \mathrm{~min}$. The same observation was made under ( $250 \mathrm{~mL}$ to $0 \mathrm{rpm}$ ) but the difference was less important since it registered $32 \%$ versus $27 \%$ after $5 \mathrm{~min}$. In these cases, our results agree with the assumption given by Furrer and Stumm. Both results show that the conditions in which the dissolution experiments are carried out influence directly the final result and that it is not possible to apply a unique assumption for all heterogeneous systems because of the nature of metal, the composition of the solution and the conditions used. Our results show also that in the first few minutes the three acids exhibited different dissolution rates of $\mathrm{Pb}$ indicating that their nature has affected the solid-liquid interaction.

The fact that citric acid was clearly the weaker reagent may be due to the fact that it is a complexing agent which contains 3 hydroxyl groups (electron exchanger) and therefore has three times more likely to bind (anchoring) strongly to the surface of lead compared to propionic or malic acids and after the first few 
minutes of reaction the $\mathrm{pH}$ values remained in acidic range $(\approx 3.2$ ) (Fig. 2a) which conserves the strong solid-liquid interactions and favors the sorption of the reaction products thus blocking the surface and preventing further dissolution.

The results show that $\mathrm{pH}$ values stabilized rapidly few minutes after the beginning of the reaction while the dissolution progressed up to $100 \%$ with propionic and malic acids. This indicates the involvement of ligands instead of protons in this stage of the reactions. In the case of citric acid, the increase in the dissolution rate was clearly observable only in the first few minutes after which the dissolution almost stopped. However, the results obtained with sodium citrate have shown higher dissolution rate compared to citric acid (Fig. 4a). This may be caused by the fact that at low pH (citric acid) the readsorption of an important part of the dissolved species (because of the high liquid-solid interaction) has blocked the active sites and consequently the reaction could not progress easily as with sodium citrate. This was confirmed by the experiment where sodium citrate was added to citric acid. In fact, after 20 min of reaction between $\mathrm{Pb}$ and citric acid the addition of sodium citrate has increased rapidly the $\mathrm{pH}$ of the solution and the dissolution reaction restarted again after it was almost stopped. Thus, the acidity played an important role on the further evolution of the dissolution.

The dissolution of $\mathrm{Pb}$ was studied in $\mathrm{HNO}_{3}$ in the presence $(350 \mathrm{rpm})$ and absence ( $0 \mathrm{rpm})$ of stirring (Fig. $5 \mathrm{a})$. The results show high dissolution rates in both cases. In fact, at $1 \mathrm{~min}$ the dissolution attained 67.3 and $80.3 \%$ at 0 and $350 \mathrm{rpm}$ respectively. In the absence of stirring the dissolution rate of $\mathrm{Pb}$ in $\mathrm{HNO}_{3}$ remained high compared to those obtained with the organic acids. After 30 min of reaction the dissolution attained 88 and $96.3 \%$ at 0 and $350 \mathrm{rpm}$ respectively. It is interesting to note that the protonation mechanism dominates in $\mathrm{HNO}_{3}$ (Fig. 5b) since the involvement of protons took longer time (up to $30 \mathrm{~min}$ ) compared to the organic acids. The progress of the reaction in $\mathrm{HNO}_{3}$ up to total dissolution while $\mathrm{pH}$ stabilized after $30 \mathrm{~min}$ was probably due to the effect of nitrates known as strong oxidants. ${ }^{24,32}$ In the literature it was reported that in nitric acid $\mathrm{H}^{+}$and $\mathrm{NO}_{3}{ }^{-}$played an inverse role leading to a competing process between oxide growth and metal dissolution and that increasing the concentration of $\mathrm{HNO}_{3}$ helps in developing and sustaining a passive film on metal surface while in diluted solution nitrate ion played the role of corrosion promoter. $^{32}$ Our experiments were carried out under diluted conditions and it seems from the results obtained that the promoting effect of nitrates was more effective than that of ligands.

There are several investigations in the literature reporting the adsorption of reaction products on the solid surface. In fact, Coles et $a .^{33}$ studied the corrosion of lead in acetic, propionic, butyric, lactic, succinic and pyruvic acid solutions at different concentrations. They found that acetic, propionic and butyric acid solutions gave almost similar results and that basic carbonate of lead $2 \mathrm{PbCO}_{3}, \mathrm{~Pb}(\mathrm{OH})_{2}$ was mainly formed as corrosion product. With pyruvic acid at higher concentration corrosion products contained carbonate as well as the acid ligand which inhibit the corrosion process. Abd-El-Rehim et $a .^{34}$ investigated the corrosion of lead in acetic, lactic, oxalic and tartaric acid solutions at $25{ }^{\circ} \mathrm{C}$. They explained lead dissolution in acetic and lactic acid solutions as a series of adsorption reactions involving catalysis by $\mathrm{L}^{-}$ions at active surface sites in monoatomic steps followed by desorption of the formed soluble salt as follows:

$$
\begin{aligned}
\mathrm{Pb}+\mathrm{L}_{(\mathrm{ads})}^{-} & \rightarrow \mathrm{PbL}_{(\mathrm{ads})}+\mathrm{e} \\
\mathrm{PbL}_{(\text {ads })}+\mathrm{L}^{-} & \rightarrow \mathrm{PbL}_{2(\mathrm{ads})}+\mathrm{e} \\
\mathrm{PbL}_{2(\mathrm{ads})} & \rightarrow \mathrm{PbL}_{2(\mathrm{aq})}
\end{aligned}
$$

where $\mathrm{L}^{-}$is $\mathrm{CH}_{3} \mathrm{COO}^{-}$or $\mathrm{CH}_{3} \mathrm{CH}(\mathrm{OH}) \mathrm{COO}^{-}$. They found that lactic acid was more corrosive than acetic acid because the former contained an extra $\mathrm{OH}$ group with lone its pair of electrons on the oxygen atom. They found also that tartaric acid was more corrosive than oxalic acid and explained it by the fact that lead tartarate was more soluble than lead oxalate. Tétreault et al. ${ }^{35}$ investigated lead corrosion in formaldehyde, formic and acetic acid vapors. They found that lead corrosion with acetic acid was higher than that with formic acid and that the latter formed a stable film composed of lead formate and formate hydroxide. All these studies pointed out the importance of the readsorption of the formed species that seem to play a key role on the progress of the dissolution process. However, the readsorption phenomenon may be lowered under certain conditions. This was observed in this study. In fact, with citric acid in the presence of stirring, increasing the collision frequency between solid particles and fluid molecules by decreasing the volume of solution has increased the dissolution rate (Fig. 6b). In the absence of stirring, the increase in dissolution rate with increasing the volume of the solution (Fig. 6d) was probably due to the fact that the solubility of the formed products increased with increasing the amount of water (dilution) which promoted also the diffusion of the dissolved molecules away from the solid surface and stimulate the chemical surface reaction (increase in mass transfer).

With propionic acid the dissolution of lead in both cases (with and without stirring) was enhanced when the fluid molecules in contact with the solid surface moved slowly. These results may be explained by the fact that propionic acid which is a volatile organic acid has only one carboxyl group that binds weakly to the solid surface compared to citric acid and that any turbulent movement in the bulk solution may prevent the surface reaction.

In the literature several studies were devoted to the effect on hydrodynamic conditions especially in the pharmaceutical field. In fact, drug dissolution testing is a fundamental part of drug product development and manufacturing and the dissolution test has been used as a quality control tool. The most commonly used dissolution test apparatus for release products is the paddle dissolution apparatus. ${ }^{36-39}$ In the paddle system the major component of fluid motion through-out the vessel was the tangential component generated by the momentum transfer from the paddle via normal stresses and the paddle rotation is in the tangential direction. The paddle rotation 
induced also secondary flows in the axial and radial directions. ${ }^{40}$ All these fluid movements create complex hydrodynamic conditions that affect the dissolution rate of drugs. In fact, there have been reports describing high variability in results due to the form of the bottom of the vessel (round or flat), to the stirring devices (e.g., paddle) and to the position of the sample in the vessel. ${ }^{\mathbf{4 1 , 4 2}}$ The effect of the position of the drug in the vessel on the dissolution rate was studied and modeled. ${ }^{43}$ It was found that different velocities exist at different points in the dissolution vessel and that the lowest dissolution rate was from the sample located in the centre under the paddle because of the lowest velocity at that position. In this study all particles of $\mathrm{Pb}$ did not participate simultaneously to the reaction since visual observations have shown that the smallest particles were the first to be dissolved. The dissolution rate was after that conducted by the agglomerate located in the bottom of the reactor, possessing lower surface area and exposed to fluid with the lowest velocity (central position). These conditions may be the cause of the retardation of the dissolution rate observed in all cases after the first stage. The agglomerate did not behave as a compact since some particles with great size were visually observed making an ellipsoidal and continual movement of several millimeters around the agglomerate in the bottom of the reactor. However we do not know whether these particles could float within the solution once their size reached a certain dimension that can allow their drag by the mainstream. If it is so, then the behavior of particles is more complex. Lead particles have high density ( $\rho$ $=11.35 \mathrm{~g} \mathrm{~cm}^{-3}$ ) this while their dispersion in the bulk was restricted to the fine particles. The use of magnetic stirring led to remove the particles from the central position and improve their dispersion in the solution. The results obtained in this case were different from those obtained with mechanical stirring. In fact, except the fact that at $1 \mathrm{~min}$ high dissolution rate was obtained corresponding to the reaction of the smallest particles, continual curves were obtained instead of straight lines and without any variation of slopes as was the case with mechanical stirring. This indicated that the same conditions were maintained inside the reactor with magnetic stirring and that the particles exposed to the fluid reacted with the same manner over the whole reaction time. Thus, the diffusion limitation induced by the use of paddle which favored the agglomeration of the particles disappeared with magnetic stirring and what remained was only the chemical reaction limitation.

Another cause that may explain the increase in the dissolution rate with magnetic stirring is that when the magnetic bar turns it enters directly into collision with the particles located in the bottom of the reactor (because of the high density of $\mathrm{Pb}$ ). The result is that the adsorbed reaction products are detached from the solid surface leading to exhibits new active sites for reaction. This phenomenon did not occur with mechanical stirrer whose paddle was located at $2 \mathrm{~cm}$ from the bottom of the reactor. Stirred conditions which may represent flowing media should be more often taken into account when investigating the behavior of metals during dissolution since they may eliminate the readsorption phenomenon and radically change the results obtained. No significant studies were found dealing with such task.

The selection of acids used provides a basis for exploring details of several important reaction mechanisms. Propionic and malic acids provide examples of protons-promoted dissolution in the initial stage. In fact, the rapid increase in $\mathrm{pH}$ value in the first few minutes was due to $\mathrm{H}^{+}$attack but the reaction was short. The stabilization of $\mathrm{pH}$ while the dissolution reaction progressed appears to be due to a ligand-promoted mechanism. In the case of citric acid the contribution of protons was less significant and ligand-promoted dissolution was weak, it is ligand adsorption at low $\mathrm{pH}$ that was the main phenomenon occurring in this case and blocking the dissolution process. The calculation of initial dissolution rate was taken at $1 \mathrm{~min}$. The initial rates of dissolution of $\mathrm{Pb}$ at experimental conditions yielded: $1.51 \times 10^{-3}, 1.36 \times 10^{-3}$ and $5.7 \times$ $10^{-4} \mathrm{~mol} \mathrm{~L}^{-1} \mathrm{~min}^{-1}$ for propionic, malic and citric acids respectively at $5 \mathrm{mM}$ and $1.65 \times 10^{-3}, 1.5 \times 10^{-3}, 1.07 \times$ $10^{-3} \mathrm{~mol} \mathrm{~L}^{-1} \mathrm{~min}^{-1}$ respectively at $50 \mathrm{mM}$. It can be seen that increasing the concentration of propionic and malic acids from $5 \mathrm{mM}$ to $50 \mathrm{mM}$ did not influence noticeably the reaction rate. This is a characterization of chemical reactions with partial order with respect to the acids close to zero. A partial order close to zero indicates that the dissolution is controlled by a mechanism that precedes the surface chemical reaction. The straight lines obtained with mechanical stirring are an indication that the diffusion was the controlling step. In the case of citric acid, increasing the concentration 10 times (from $5 \mathrm{mM}$ to $50 \mathrm{mM}$ ) increased the initial rate by approximately 2 times (from $5.7 \times 10^{-4} \mathrm{~mol} \mathrm{~L}^{-1} \mathrm{~min}^{-1}$ to $1.07 \times 10^{-3} \mathrm{~mol} \mathrm{~L}^{-1} \mathrm{~min}^{-1}$ ). In this case the dissolution rate was more dependent on acid concentration than with propionic and malic acids. It is likely that its strong complexant characteristics played a role in this result.

It is difficult to model kinetically the behavior of $\mathrm{Pb}$ particles over the whole reaction time since the conditions such as the velocity of the fluid into the reactor, the dispersion of the particles into the solution and their surface exposed to fluid changed with time and with the location into the reactor. The changes in the slopes as the reactions progressed were an indication that new conditions prevailed.

On the other hand, the results obtained showed that $\mathrm{Pb}$ was easily dissolved under mild conditions. It attained 100\%, 92.1 and $47.6 \%$ after 35 min with propionic, malic and citric acids respectively at $5 \mathrm{mM}$. These observations may be useful for a hydrometallurgical application when a green process is chosen to separate $\mathrm{Pb}$ from industrial wastes.

These results support also previous finding about the potential risk of $\mathrm{Pb}$ particles spread in environment. In fact, Giusti et $a l .{ }^{44}$ found that $40-50 \%$ of $\mathrm{Pb}$ from atmospheric particles was released in the first few minutes into seawater, freshwater and $1 \mathrm{M}$ solution of $\mathrm{MgCl}_{2}$ and that only little or no further dissolution occurs after $30 \mathrm{~min}$ in freshwater. Similar results were obtained for $\mathrm{Pb}$ dissolution in acid-rain water and lake water. ${ }^{45}$ Thus, the presence of soluble ligands in soils and sediments rich with organic matter might have an important effect on the mobilization of metals especially 
those with relatively small particles size. Metallic lead in the form of particles could react easily with existing organic acids in soils and water especially with those having low number of functional groups making it easily dispersed into the environment.

\section{Conclusion}

The results obtained in this work show that the system studied was complex where the effect of particle size, stirring device, the nature of organic acid and of the metal, all interfere together giving rise to a unique solid-liquid system. In fact it was observed that propionic acid which contains low number of functional groups was more efficient in $\mathrm{Pb}$ dissolution than citric acid known as strong dissolving agent under almost all conditions. It was also observed that changing the hydrodynamic conditions changes the limitation step. In fact, the straight lines of $\mathrm{Pb}$ dissolution versus time obtained with mechanical stirring were changed to curves with magnetic one. This indicates that diffusional limitations were replaced by chemical reaction limitation. In the literature the hydrodynamic conditions are not taken into account during the dissolution studies of minerals and any assumption posed should integrate all parameters to draw the correct conclusions on the dissolution conditions.

\section{Acknowledgements}

This work was financially supported by the Ministry of Higher Education and Scientific Research of Algeria (CNEPRU Project No. J0101120110047).

\section{References}

1 F. Khalil, International Conference on Green Buildings and Sustainable Cities, Procedia Eng., 2011, 21, 760-766.

2 F. Ramade, Proceedings of the 2nd European Conference on Ecotoxicology, Sci. Total Environ., 1993, 134, 97-107.

3 I. Abdel-Saheb, A. P. Schwab, M. K. Banks and B. A. Hetrick, Water, Air, Soil Pollut., 1994, 78, 73-82.

4 US Environmental Protection Agency (US EPA), 40 CFR Part 745, Code of Fed. Reg, 2001, vol. 66, pp. 1206-1240.

5 A. P. Schwab, Y. He and M. K. Banks, Chemosphere, 2005, 61, 856-866.

6 M. Mench and E. Martin, Plant Soil, 1991, 132, 187-196.

7 L. H. Wu, Y. M. Luo, P. Christie and M. H. Wong, Chemosphere, 2003, 50, 819-822.

8 E. P. Manley and L. J. Evans, Soil Sci., 1986, 141, 106-112.

9 G. Sposito, The Chemistry of Soils, Oxford Press, London, 1989, p. 42.

10 M. Robert and J. Berthelin, Soil Science Society of America, Madison, WI, 1986, pp. 453-495.

11 D. L. Jones, Plant Soil, 2004, 205, 25-44.

12 A. Niklasson, L. G. Johansson and J. E. Svensson, Corros. Sci., 2008, 50, 3031-3037.
13 C. Chiavari, C. Martini, D. Prandstraller, A. Niklasson, L. G. Johansson, J. E. Svensson, A. Åslund and C. J. Bergsten, Corros. Sci., 2008, 50, 2444-2455.

14 A. Niklasson, L. G. Johansson and J. E. Svensson, J. Electrochem. Soc., 2007, 154, C618-C625.

15 J. Tétreault, E. Cano, M. Van Bommel, D. Scott, M. Dennis, M. G. Barthés-Labrousse, L. Minel and L. Robbiola, Stud. Conserv., 2003, 48, 237-250.

16 S. T. Puglieri, L. A. Dalva de Faria and A. Cavicchioli, Vib. Spectrosc., 2014, 71, 24-29.

17 Y. Ma and K. Qiu, Waste. Manag., 2015, 40, 151-156.

18 C. S. Chen, Y. J. Shih and Y. H. Huang, Waste. Manag., 2016, 52, 212-220.

19 X. Zhu, X. He, J. Yang, L. Gao, J. Liu, D. Yang, X. Sun, W. Zhang, Q. Wang and R. V. Kumar, J. Hazard. Mater., 2013, 250-251, 387-396.

20 M. S. Sonmez and R. V. Kumar, Hydrometallurgy, 2009, 95, 53-60.

21 M. S. Sonmez and R. V. Kumar, Hydrometallurgy, 2009, 95, 82-86.

22 M. Niinae, K. Nishigaki and K. Aoki, Mater. Trans., 2008, 49, 2377-2382.

23 N. Habbache, N. Alane, S. Djerad and L. Tifouti, Chem. Eng. J., 2009, 152, 503-508.

24 I. Boukerche, S. Djerad, L. Benmansour, L. Tifouti and K. Saleh, Corros. Sci., 2014, 78, 343-352.

25 W. Stumm, Colloids Surf., A, 1997, 120, 143-166.

26 A. E. Martell and M. Calvin, Chemistry of the metal chelate compound, Prentice-Hall, Inc., New York, 1952.

27 A. A. Pohlman and J. G. Coll, J. Environ. Qual., 1985, 15, 86.

28 G. Furrer and W. Stumm, Geochim. Cosmochim. Acta, 1986, 50, 1847-1860.

29 W. Stumm, Chemical Processes at the Particle-Water Interface, Wiley-Interscience, New York, 1987, p. 197.

30 O. S. Pokrovsky, J. Schott and A. Castillo, Geochim. Cosmochim. Acta, 2005, 69, 905-918.

31 A. E. Martell and R. M. Smith, Critical stability constants, New York, London, Plenum Press, 1974-1989.

32 S. M. Sayed and H. A. El Shayeb, Surf. Coat. Technol., 1986, 29, 51-58.

33 E. L. Coles, J. G. Gibson and R. M. Hinde, J. Appl. Chem., 1958, 341-348.

34 S. S. Abd-El-Rehim, N. H. Amin, L. I. Ali and N. F. Mohamed, J. Chem. Technol. Biotechnol., 1998, 72, 197-201.

35 J. Tétreault, E. Cano, M. Van Bommel, D. Scott, M. Dennis, M. G. Barthés-Labrousse, L. Minel and L. Robbiola, Stud. Conserv., 2003, 48, 237-250.

36 L. G. McCarthy, G. Bradley, J. C. Sexton, O. I. Corrigan and A. M. Healy, AAPS PharmSciTech, 2004, 5, 31.

37 A. Dokoumetzidis, V. Papadopoulou, G. Valsami and P. Macheras, Int. J. Pharm., 2008, 355, 114-125.

38 A. Dokoumetzidis, V. Papadopoulou and P. Macheras, Pharm. Res., 2006, 23, 256-261.

39 D. M. D'Arcy, O. I. Corrigan and A. M. Healy, Eur. J. Pharm. Sci., 2006, 27, 259-267. 
40 L. G. McCarthy, C. Kosiol, A. M. Healy, G. Bradley, J. C. Sexton and O. I. Corrigan, AAPS PharmSciTech, 2003, 4, 22.

41 S. A. Qureshi and J. Shabnam, Eur. J. Pharm. Sci., 2001, 12, 271-276.

42 V. A. Gray and B. B. Hubert, Pharmacopeial Forum, 1994, 20, 8571-8573.
43 D. M. D'Arcy, O. I. Corrigan and A. M. Healy, J. Pharm. Pharmacol., 2005, 57, 1243-1250.

44 L. Giusti, Y. L. Yang, C. N. Hewitt, J. Hamilton-Taylor and W. Davison, Atmos. Environ., Part A, 1993, 27, 1567-1578.

45 Q. W. Elzerman, T. J. Overcamp and L. F. Owen, Abstracts, Am. Chem. Soc. Div. of Enron. Chem, Las Vegas, Nev, 1980. 